\title{
Initial Experiences of Retropubic Radical Prostatectomy Including Antegrade Nerve Sparing, Continuous Anastomosis, and Preservation of Endopelvic Fascia
}

\author{
Se Yun Kwon, Kyung Seop Lee
}

Department of Urology, Dongguk University College of Medicine, Gyeongju, Korea

Purpose: We compared retropubic radical prostatectomy (RRP) with various laparoscopic radical prostatectomy procedures with RRP as previous performed in our institution.

Materials and Methods: Demographics, perioperative and functional outcomes of 78 patients that underwent modified RRP (mRP; N=53) or established RRP (eRP; N=25) at our institution from January 2013 to December 2018 were evaluated retrospectively. Postoperative incontinence and erectile dysfunction are involved functional outcomes. During the modified procedure, with preserving endopelvic fascia, the prostate was dissected in an antegrade fashion with bilateral nerve sparing, and then urethrovesical anastomosis was performed with continuous suture.

Results: The mean age was older in $\mathrm{mRP}(68.7 \pm 5.3$ years) than $\mathrm{mRP}(65.9 \pm 5.0$ years) and mean prostate volume was larger in $\mathrm{mRP}(40.1 \pm 18.6 \mathrm{~mL})$ than $\mathrm{eRP}(30.4 \pm 14.0 \mathrm{~mL})$. Mean operative time was longer in eRP (227.0 \pm 111.1 minutes) than mRP (154.6 \pm 31.6 minutes) and estimated blood loss and complicate rate were similar in 2 groups. The pathologic stage was all T2 stage in eRP, however, in MRP T2 stage was 31 and T3 stage was 22. The pathologic Gleason score was higher in $\mathrm{mRP}$ than eRP $(p=0.001)$. Positive surgical margin was significantly higher in $\mathrm{mRP}$, however, biochemical recurrence was insignificantly higher in mRP. Incontinence rates at 3 and 12 months after eRP decreased from $96.0 \%$ to $28.0 \%$ and after mRP decreased from $49.1 \%$ to $7.5 \%$. Overall postoperative potency rate at 12 months was significant different in eRP and mRP groups ( $8.0 \%$ and $34.0 \%)$. Conclusions: The mRP was found to have favorable functional outcome and short operative time. This technique might be adopted by inexperienced urologic surgeons as a standard procedure. (Korean J Urol Oncol 2020;18:47-52)

Key Words: Radical prostatectomy • Anastomosis • Endopelvic fascia

\section{INTRODUCTION}

Radical prostatectomy (RP) is the standard treatment for

Received January 2, 2020, Revised January 23, 2020,

Accepted January 30, 2020

Corresponding Author: Kyung Seop Lee

Department of Urology, Dongguk University College of Medicine,

123 Dongdae-ro, Gyeongju 38066, Korea

E-mail: ksleemd@dongguk.ac.kr

Tel: +82-54-770-8265, Fax: +82-54-770-8378

ORCID: https://orcid.org/0000-0002-0554-4272 localized prostate cancer $^{1}$ and has been extended to high-risk prostate cancer patients. ${ }^{2,3}$ Recently, various types of surgery have been performed with good results, especially, RP using robot-assisted laparoscopy, which has produced good results in terms of postoperative pain relief and bleeding loss. ${ }^{4,5}$ In addition, some studies have reported lower incidences of erection dysfunction and incontinence. ${ }^{4,5}$

However, there is no significant difference in the functional outcome of robot-assisted laparoscopic radical prostatectomy (RALP) and open RP (ORP), ${ }^{6,7}$ though RALP has

This is an Open Access article distributed under the terms of the Creative Commons Attribution Non-Commercial License (http://creativecommons.org/licenses/by-nc/4.0/) which permits unrestricted non-commercial use, distribution, and reproduction in any medium, provided the original work is properly cited. 2020 (C) Copyright The Korean Urological Oncology Society and The Korean Prostate Society. All Rights Reserved. 
been shown to incur considerable costs as compared with ORP. ${ }^{8,9}$ In addition, RALP requires a learning period as much as open procedure, ${ }^{10,11}$ and it is a reality that robotic systems are expensive and therefore probably limited to larger hospitals. ${ }^{12}$

On the other hand, ORP has been used for a considerable time, is relatively inexpensive, ${ }^{9}$ and can be implemented without a robotic system. Recently, RALP procedure has become widely adopted, and RALP is now being applied to ORP. ${ }^{13,14}$ Thus, we performed ORP in a manner based to RALP procedure such as antegrade dissection of prostate and continuous anastomosis.

In this study, we compared ORP applying procedure which was usually used in RALP such as antegrade dissection and continuous vesicourethral anastomosis (VUA) with ORP as previous performed in our institution.

\section{MATERIALS AND METHODS}

\section{Patients}

We retrospectively analyzed the records of 78 patients that underwent modified RRP (mRP; $n=53$ ) or established RRP (eRP; $n=25$ ) at our institution from January 2013 to December 2018.

This study was approved by the Institutional Review Board and ethics committee of Dongguk University Gyeongju Hospital (110757-201903-HR-03-02). The eRP and $\mathrm{mRP}$ were both performed by 2 surgeons, they have performed a similar number of ORP.

The demographic parameters analyzed included age, body mass index (BMI) and prostate volume. The pathological data analyzed included preoperative prostate-specific antigen (PSA) level, postoperative Gleason score and pathologic stage. To evaluate operative outcomes, we compared operative times, estimated blood losses (EBLs), and transfusion and complication rates. To analyze functional outcomes, we compared incidences of postprostatectomy incontinence (PPI) and erectile dysfunction, and to analyze oncologic outcomes, we compared positive surgical margin and biochemical recurrence (BCR) rates. The median follow-up period was 33.0 months.

\section{Surgical Technique}

The eRP was performed with the patient supine. After re- moving preprostatic fat, the superficial dorsal vein was coagulated and divided, and puboprostatic and endopelvic ligaments were exposed. The endopelvic fascia was opened bilaterally and dissected caudally. The surgeon then tunneled within the endopelvic fascia and made the plane between the dorsal venous complex and the urethra. The deep dorsal venous complex was then ligated and then apical dissection was performed. The prostate was dissected in a retrograde fashion with or without preserving bilateral nerves to achieve almost complete mobilization. The bladder neck was incised anteriorly at the prostatovesicular junction, and the vas deferens was divided and ligated. Seminal vesicles were carefully dissected free from the pelvic plexus with direct visualization and ligation of small arterial branches. Urethrovesical anastomosis was performed in an interrupted manner. No filling test was performed and the Foley catheter used was removed 14 to 21 days after surgery under cystographic control.

For mRP, the superficial dorsal vein and preprostatic fat were processed in the same manner as described for eRP. After lateral bladder and prostate dissection, the bladder neck was dissected anteriorly. After dissection of vas deference and seminal vesicles, the prostate was dissected in an antegrade fashion while preserving bilateral nerves. Finally, the urethra was cut at the prostate apex. After careful hemostasis, urethrovesical anastomosis was performed in a continuous manner. A 2-strand running suture was placed appropriately on both posterior sides first and then anastomosis was performed from 3:00 and 9:00 o'clock to 12:00 o'clock while maintaining tension at the posterior anastomosis site using a needle holder. A filling test was performed and the Foley catheter was removed 10 days after surgery under cystographic control.

\section{Definition and Assessment of Continence}

Continence was defined as no pad usage and no urine leakage, as determined by patient responses. Patients were asked the following question: "How many pads or adult diapers have you used daily to control leakage during the past 4 weeks?" Recovery of continence was evaluated routinely at 3,6 , and 12 months after surgery.

\section{Definition of Postoperative Potency}

Postoperative potency was defined as the ability to ach- 
ieve penetration $\geq 50 \%$ of the time and to maintain an erection significant enough for penetration $\geq 50 \%$ of the time using questions 2 and 3 of the International Index of Erectile Function-5 survey at 12 months after surgery.

\section{Definition of BCR}

BCR was defined as a serum PSA of $>0.2 \mathrm{ng} / \mathrm{mL}$ for 2 consecutive measurements.

\section{Follow-up Evaluation}

After hospital discharge, patients were counseled to undergo a serum PSA test every 3 months for the first 2 years, every 6 months for the next 3 years, and then annually.

\section{Statistical Analysis}

Demographics and perioperative outcomes were analyzed using the chi-square test and the Mann-Whitney test. The chi-square test was used to analyze incontinence rates and postoperative potency rates at the above-mentioned times. The analysis was performed using PASW Statistics 18.0 (SPSS Inc., Chicago, IL, USA). For all comparisons, a p-value of $<0.05$ was considered statistically significant.

\section{RESULTS}

The mRP and eRP groups each contained 53 and 25

Table 1. Demographic data and operative parameter

\begin{tabular}{lccc}
\hline \multicolumn{1}{c}{ Variable } & $\mathrm{eRP}(\mathrm{n}=25)$ & $\mathrm{mRP}(\mathrm{n}=53)$ & $\mathrm{p}$-value \\
\hline Age $(\mathrm{yr})$ & $65.9 \pm 5.0$ & $68.8 \pm 5.3$ & 0.025 \\
Body mass index & $23.8 \pm 2.2$ & $24.5 \pm 2.9$ & 0.317 \\
$\left(\mathrm{~kg} / \mathrm{m}^{2}\right)$ & & & \\
Prostate volume $(\mathrm{mL})$ & $30.4 \pm 14.0$ & $40.1 \pm 18.6$ & 0.022 \\
Preoperative PSA & & & 0.871 \\
$\quad(\mathrm{ng} / \mathrm{mL})$ & & & \\
$\quad<10$ & $19(76.0)$ & $37(69.8)$ & \\
$10-20$ & $4(16.0)$ & $9(17.0)$ & \\
$>20$ & $2(8)$ & $6(11.3)$ & \\
Operative time (min) & $227.0 \pm 111.1$ & $154.6 \pm 31.6$ & 0.001 \\
Estimated blood loss & $238.8 \pm 128.0$ & $272.64 \pm 139.5$ & 0.308 \\
$\quad(\mathrm{~mL})$ & & & \\
No. of complications & $3(12.0)$ & $3(5.7)$ & 0.327 \\
\hline
\end{tabular}

Values are presented as mean \pm standard deviation or number (\%). eRP: established retropubic radical prostatectomy, mRP: modified established retropubic radical prostatectomy, PSA: prostate-specific antigen. patients. Mean age was greater in the $\mathrm{mRP}$ group $(68.7 \pm 5.3$ years vs. $65.9 \pm 5.0$ years, $\mathrm{p}=0.025)$ and mean prostate volume was larger $(40.1 \pm 18.6 \mathrm{~mL}$ vs. $30.4 \pm 14.0 \mathrm{~mL}, \mathrm{p}=0.022)$. BMI was not significantly different between the 2 groups.

Mean operative time was shorter in the mRP group (154.6 \pm 31.6 minutes vs. $227.0 \pm 111.1$ minutes, $\mathrm{p}=0.001$ ). EBL, transfusion and complicate rates were similar in the 2 groups (Table 1). The mean duration of catheterization was similar in both groups (17.6 \pm 8.2 days vs. 16.1 \pm 3.9 days, $\mathrm{p}=0.373$ ).

No significant intergroup difference was found for preoperative PSA $(10.1 \pm 9.0 \mathrm{ng} / \mathrm{mL}$ vs. $9.7 \pm 8.7 \mathrm{ng} / \mathrm{mL}, \mathrm{p}=0.825)$. In the eRP group all 25 patients were of pathologic stage T2 whereas in the mRP group, 31 were of stage T2 and 22 were of stage T3. Mean pathologic Gleason score was significantly higher in the mRP group $(p=0.001)$. Positive surgical margin rate was significantly higher in mRP (30.2\% vs. $8.0 \%, p=0.03)$, however, BCR was insignificantly higher in mRP (Table 2).

Incontinence rates at 3, 6, and 12 months after eRP were $96 \%, 60 \%$, and $28 \%$ and after mRP were $49.1 \%, 20.7 \%$, and $7.5 \%(\mathrm{p}=0.001, \mathrm{p}=0.001$, and $\mathrm{p}=0.015)$ (Table 3).

Overall postoperative potent rates at 12 months were significantly different (eRP $8.0 \%$ and $\mathrm{mRP} 34.0 \%, \mathrm{p}=0.014$ ) (Table 4).

Table 2. Pathologic data

\begin{tabular}{lccc}
\hline \multicolumn{1}{c}{ Variable } & $\begin{array}{c}\text { eRP } \\
(\mathrm{n}=25)\end{array}$ & $\begin{array}{c}\mathrm{mRP} \\
(\mathrm{n}=53)\end{array}$ & $\mathrm{p}$-value \\
\hline Pathologic stage & & & 0.001 \\
T2 & $25(100)$ & $31(58.5)$ & \\
T3 & $0(0)$ & $22(41.5)$ & \\
Pathologic Gleason score & & & 0.001 \\
6 & $9(36.0)$ & $2(3.8)$ & \\
7 & $10(45.5)$ & $26(49.0)$ & \\
8 & $5(20.0)$ & $9(17.0)$ & \\
9 & $1(4)$ & $15(28.3)$ & \\
10 & $0(0)$ & $1(1.9)$ & \\
Positive surgical margin & $2(8.0)$ & $16(30.2)$ & 0.030 \\
Biochemical recurrence & $7(28.0)$ & $10(18.9)$ & 0.362 \\
\hline
\end{tabular}

Values are presented as number (\%).

eRP: established retropubic radical prostatectomy, mRP: modified established retropubic radical prostatectomy. 
Table 3. Incontinence and potency rates between $\mathrm{eRP}$ and $\mathrm{mRP}$ at 3 and 12 months

\begin{tabular}{llrl}
\hline & \multicolumn{2}{c}{ Incontinence $(\%)$} & p-value \\
\cline { 2 - 3 } & eRP & mRP & \\
\hline 3 Months & 96.0 & 49.1 & 0.001 \\
6 Months & 60.0 & 20.7 & 0.001 \\
12 Months & 28.0 & 7.5 & 0.015 \\
\hline
\end{tabular}

eRP: established retropubic radical prostatectomy, mRP: modified established retropubic radical prostatectomy.

\section{DISCUSSION}

ORP is a relatively sophisticated procedure that is performed in a confined space and produces good oncologic and functional results. Therefore, difference in outcomes may be substantial as patients' preferences for robotic surgery are increasing regardless of surgical results. ${ }^{15,16}$

However, in reality, robot surgery cannot be used for all procedures as many medical institutions do not have robotic systems and the number of technicians capable of managing robots is limited. ${ }^{12}$ On the other hand, surgeons skilled at robotic surgery increasingly have little ORP experience. Generally, although robotic surgery is costly, when oncologic and functional outcomes are considered many consider it is cost-effective. Nonetheless, ORP is viewed as an important skill because it allows prostate cancer to be treated without special equipment.

ORP usually involves more blood loss than laparoscopic surgery, and securing an operative field of view because it is performed in a narrow space. Unlike robotic surgery, nerve preservation is not easy during performing prostatectomy. Furthermore, the operative time required for ORP is less than that required for RALP. In addition, the extraperitoneal approach is mainly used, which means there is no possibility of bowel injury, and thus, ORP is thought to have a lower complication rate than RALP that usually performed with the intraperitoneal approach.

Recently, various robot operations have been applied to ORP and good results have been reported. ${ }^{4-7}$ The most significant difference between eRP and $\mathrm{mRP}$ at our institution are the preservation of endopelvic fascia, antegrade nerve sparing, and urethrovesical anastomosis.

VUA is another important step during RP, and has been found to affect hospital outcomes. The eRP is a modified
Table 4. Postoperative potency rates between eRP and mRP at 6 and 12 months

\begin{tabular}{ccccccccc}
\hline & \multicolumn{3}{c}{6 Months } & & \multicolumn{3}{c}{12 Months } \\
\cline { 2 - 3 } \cline { 7 - 9 } & eRP & mRP & p-value & & eRP & mRP & p-value \\
\hline Potency (\%) & 8.0 & 28.3 & 0.043 & & 8.0 & 34.0 & 0.014 \\
\hline
\end{tabular}

eRP: established retropubic radical prostatectomy, mRP: modified established retropubic radical prostatectomy.

version of the initial VUA technique described by Walsh, ${ }^{1}$ which makes use of interrupted sutures and is commonly used in modern practice. However, interrupted suturing techniques are not used during RALP or laparoscopic RP (LRP) because of technical difficulties, and thus, VUA using the continuous suturing technique introduced by Van Velthoven et al. ${ }^{17}$ and modified by Menon et al. ${ }^{18}$ is widely used. Several RALP and LRP studies using VUA and watertight continuous suturing have reported successful urethral catheter removal as early as 7 days after surgery. ${ }^{19,20}$ In addition to its use during RALP and LRP, some authors have suggested VUA with continuous suturing in open RRP could reduce VUA site leakage and alleviate PPI. ${ }^{21,22}$

Before the introduction of mRP, we sutured the deep venous complex after opening endopelvic fascia, but this process created broad levator muscle injury, which is known to be related to urinary incontinence. In addition, bleeding from pelvic muscles and adjacent tissues caused during this process can often obstruct the surgical field. These situations can be prevented by preserving endopelvic fascia, and nerve-sparing procedures tend to be easier when endopelvic fascia is preserved because it is not detached from muscle and the neurovascular bundle is relatively well dissected. However, the technique preserving endopelvic fascia is difficult in the narrow surgical field of RRP, which is adopted to prevent excessive bleeding. Nevertheless, understanding of pelvic anatomy gained through experiences of robot surgery enabled us to perform this technique. Our procedure of VUA has several advantages because continuous sutures are more watertight than interrupted sutures and we haven't experienced a tear in the suture intraoperatively. Also, this procedure shortens the duration of Foley catheter indwelling.

At our institution, $\mathrm{mRP}$ has reduced operation times and improved functional results as compared with eRP. 
Although, more patients with high-risk prostate cancer were included in group treated by $\mathrm{mRP}$, they showed excellent oncologic results over a follow-up period and similar complications were observed compared to eRP.

This study is limited by its retrospective, single-center design and a relatively small sample size. However, this study shows mRP can be improved by adopting what is essentially a RALP procedure. Moreover, our procedure can help urologists trained to use a robot system but affiliated with medical institutions without such a system.

\section{CONCLUSIONS}

The modified RP was found to produce favorable functional outcomes and good operative outcomes in the short-term. We suggest the technique be adopted by inexperienced urologic surgeons, and that this procedure could potentially be used by surgeons trained in robot surgery at institutions without a robot system.

\section{CONFLICT OF INTEREST}

The authors claim no conflicts of interest.

\section{REFERENCES}

1. Walsh PC. Anatomic radical prostatectomy: evolution of the surgical technique. J Urol 1998;160:2418-24.

2. Matulay JT, DeCastro GJ. Radical prostatectomy for high-risk localized or node-positive prostate cancer: removing the primary. Curr Urol Rep 2017;18:53.

3. Colicchia M, Sharma V, Abdollah F, Briganti A, Jeffrey Karnes R. Therapeutic value of standard versus extended pelvic lymph node dissection during radical prostatectomy for high-risk prostate cancer. Curr Urol Rep 2017;18:51.

4. Rapoport L, Yossepowitch O, Shpot E, Chinenov D, Chernov Y, Yurova M, et al. Radical prostatectomy performed via robotic, transperitoneal and extraperitoneoscopic approaches: functional and early oncological outcomes. Cent European J Urol 2018;71:378-85.

5. Du Y, Long Q, Guan B, Mu L, Tian J, Jiang Y, et al. Robot-assisted radical prostatectomy is more beneficial for prostate cancer patients: a system review and meta-analysis. Med Sci Monit 2018;24:272-87.

6. Yaxley JW, Coughlin GD, Chambers SK, Occhipinti S, Samaratunga H, Zajdlewicz L, et al. Robot-assisted laparoscopic prostatectomy versus open radical retropubic pros- tatectomy: early outcomes from a randomised controlled phase 3 study. Lancet 2016;388:1057-66.

7. Nossiter J, Sujenthiran A, Charman SC, Cathcart PJ, Aggarwal A, Payne H, et al. Robot-assisted radical prostatectomy vs laparoscopic and open retropubic radical prostatectomy: functional outcomes 18 months after diagnosis from a national cohort study in England. Br $\mathrm{J}$ Cancer 2018;118:489-94.

8. Schroeck FR, Jacobs BL, Bhayani SB, Nguyen PL, Penson $\mathrm{D}, \mathrm{Hu} \mathrm{J}$. Cost of new technologies in prostate cancer treatment: systematic review of costs and cost effectiveness of robotic-assisted laparoscopic prostatectomy, intensitymodulated radiotherapy, and proton beam therapy. Eur Urol 2017;72:712-35.

9. Mukherjee K, Kamal KM. Variation in prostate surgery costs and outcomes in the USA: robot-assisted versus open radical prostatectomy. J Comp Eff Res 2019;8:143-55.

10. Dias JA Neto, Dall'oglio MF, Colombo JR Jr, Coelho RF, Nahas WC. The influence of previous robotic experience in the initial learning curve of laparoscopic radical prostatectomy. Int Braz J Urol 2017;43:871-9.

11. Sivaraman A, Sanchez-Salas R, Prapotnich D, Yu K, Olivier F, Secin FP, et al. Learning curve of minimally invasive radical prostatectomy: comprehensive evaluation and cumulative summation analysis of oncological outcomes. Urol Oncol 2017;35:149.

12. Tsukamoto T, Tanaka S. Robot-assisted laparoscopic radical prostatectomy for patients with prostatic cancer and factors promoting installation of the robotic surgical equipment-questionnaire survey. Hinyokika Kiyo 2015;61:3218.

13. Kwon SY, Lee JN, Ha YS, Choi SH, Kim TH, Kwon TG. Open radical prostatectomy reproducing robot-assisted radical prostatectomy: involving antegrade nerve sparing and continuous anastomosis. Int Braz J Urol 2017;43:1043-51.

14. Lee SW, Han DH, Lee KS, Jeon SS. Effect of continuous urethro-vesical anastomosis technique in incontinence after radical retropubic prostatectomy, 1:1 matching study. Int Neurourol J 2015;19:113-9.

15. Antonelli A, Palumbo C, Noale M, Porreca A, Maggi S, Simeone $\mathrm{C}$, et al. Impact of surgical approach on patient-reported outcomes after radical prostatectomy: a propensity score-weighted analysis from a multicenter, prospective, observational study (The Pros-IT CNR Study). Urol Int 2019;103:8-18.

16. Long JA, Poinas G, Fiard G, Leprêtre M, Delaitre-Bonnin C, Rébillard X, et al. Robot assisted radical prostatectomy: what are the evidences at the time of a specific funding? Prog Urol 2017;27:146-57.

17. Van Velthoven RF, Ahlering TE, Peltier A, Skarecky DW, Clayman RV. Technique for laparoscopic running urethrovesical anastomosis:the single knot method. Urology 
2003;61:699-702.

18. Menon M, Shrivastava A, Kaul S, Badani KK, Fumo M, Bhandari M, et al. Vattikuti Institute prostatectomy: contemporary technique and analysis of results. Eur Urol 2007;51:648-57.

19. Nadu A, Salomon L, Hoznek A, Olsson LE, Saint F, de La Taille A, et al. Early removal of the catheter after laparoscopic radical prostatectomy. J Urol 2001;166:1662-4.

20. Teber D, Erdogru T, Cresswell J, Gözen AS, Frede T, Rassweiler JJ. Analysis of three different vesicourethral anastomotic techniques in laparoscopic radical prostatectomy. World J Urol 2008;26:617-22.

21. Forster JA, Palit V, Myatt A, Hadi S, Bryan NP. Technical description and outcomes of a continuous anastomosis in open radical prostatectomy. BJU Int 2009;104:929-33.

22. Lim JH, Park CM, Kim HK, Park JY. Comparison of perioperative outcomes between running versus interrupted vesicourethral anastomosis in open radical prostatectomy: a single-surgeon experience. Korean J Urol 2015;56: 443-8. 